\title{
Design of Controlled-Release Morphine Suppositories Containing Polyglycerol Ester of Fatty Acid
}

\author{
Toshihito TaKatori, ${ }^{a, d}$ Kazumitsu Yamamoto, ${ }^{b}$ Toshikazu Yamaguchi,${ }^{c}$ Kazutaka Higaki, ${ }^{d}$ and \\ Toshikiro KIMURA ${ }^{*, d}$ \\ ${ }^{a}$ Pharmaceutical Technology Section, Manufacturing Technology \& Engineering, Dainippon Pharmaceutical Co., Ltd.; \\ 1450 Yasuzuka, Suzuka, Mie 513-0818, Japan: ${ }^{b}$ Pharmaceutical Research \& Technology Center, Dainippon \\ Pharmaceutical Co., Ltd.; 33-94 Enoki, Suita, Osaka 564-0053, Japan: ${ }^{c}$ Pharmaceutical Research \& Technology Center, \\ Dainippon Pharmaceutical Co., Ltd.; 1-5-51 Ebie, Fukushima-ku, Osaka 553-0001, Japan: and ${ }^{d}$ Department of \\ Pharmaceutics, Faculty of Pharmaceutical Sciences, Okayama University; 1-1-1 Tsushima-naka, Okayama 700-8530, \\ Japan. Received March 15, 2005; accepted May 6, 2005; published online May 12, 2005
}

Controlled-release morphine suppositories were prepared by utilizing polyglycerol ester of fatty acid (PGEF). The addition of PGEF to fatty suppository base Witepsol H15 resulted in a decrease of morphine release rate from suppositories. Among PGEFs examined, decaglycerol heptabehenate (HB750) was the most effective additive for the controlled-release of morphine from fatty suppositories. The apparent viscosity of suppository bases increased with the increase in $\mathrm{HB} 750$ content, and good correlation was observed between the apparent viscosity of suppository bases at $37^{\circ} \mathrm{C}$ and the amount of $\mathrm{HB} 750$ added in the mixed base. The in vitro release rate of morphine was decreased by the addition of $\mathrm{HB750}$ and the release rate constant (Higuchi's rate constant) for morphine release was significantly correlated with the HB750 content in the mixed bases as well as the apparent viscosity of mixed bases, indicating that the release of morphine from the mixed bases could be regulated by the $\mathrm{HB} 750$ content in the mixed bases. After rectal administration of Witepsol H-15-HB750 mixed suppositories to dogs, plasma concentrations of morphine did not increase rapidly at early time periods, but relatively high levels of morphine in plasma were sustained for longer time periods. Mean residence time of morphine was considerably prolonged without changing relative bioavailability in the case of the mixed base suppositories containing 15-17\% HB750, compared with the Witepsol H15 suppository, clearly indicating that the mixed bases containing HB750 are expected to be useful for the design of controlled-release morphine suppositories.

Key words morphine suppository; fatty suppository; polyglycerol ester of fatty acid; viscosity; release control

Morphine is widely used for the management of severe cancer pain. The oral route is the first choice in administering medication to relieve it, but clinical experience has shown that alternative routes of administration should be employed for patients suffering from nausea and vomiting. Furthermore, as morphine is subjected to the extensive first-pass metabolism after oral administration, the rectal administration of morphine, which can partially avoid the hepatic first-pass metabolism, leads to higher bioavailability, compared with the oral dosing. ${ }^{1)}$ Therefore, the rectal route is very important for the management of severe pain by morphine. ${ }^{2)}$ Morphine suppository preparations used clinically are not of the sustained-release type, so more than 3 doses per day are required to maintain the analgesic effect due to the rapid elimination of morphine. Therefore, controlled-release dosage forms are considered to be particularly appropriate for morphine. Sustained-release suppositories of morphine have been investigated, and the release of morphine was controlled by hydrogel, ${ }^{3)}$ modified suppository base such as light anhydrous silicic acid $\left(\text { Aerosil }^{\circledR}\right)^{4,5)}$ or alginic acid. ${ }^{6,7)}$ In another case, a controlled-release morphine tablet was investigated for rectal use. ${ }^{8)}$

Polyglycerol ester of fatty acid (PGEF) is a solid fat and has excellent characteristics as an additive of controlled-release suppository. ${ }^{9,10)}$ PGEFs have a well affinity with the fatty suppository bases, and the matrix bases can be homogeneously prepared by adding PGEFs to suppository bases, which may provide a stable controlled-release system. In the present study, a novel type of controlled-release suppositories has been developed for morphine by using PGEF as an addi- tive of suppository. Physicochemical characteristics of the suppositories and the release properties of morphine from the suppositories were evaluated in an in vitro study. Furthermore, in vivo absorption studies were performed in beagle dogs.

\section{MATERIALS AND METHODS}

Materials Morphine hydrochloride was obtained from Dainippon Pharmaceutical Co., Ltd. (Osaka, Japan). Witepsol H15 was purchased from Mitsuba Trading Co., Ltd. (Tokyo, Japan), and hexaglycerol pentastearate (PS500), decaglycerol decastearate (DAS750) and decaglycerol heptabehenate (HB750) from Sakamoto Yakuhin Kogyo Co., Ltd. (Osaka). Other reagents used were analytical or special reagent grade commercial products.

Preparation of Suppositories PS500, DAS750 and HB750 were chosen as PGEF in the present study. Suppositories were prepared according to the fusion method. At first, PGEF (PS500, DAS750 or HB750) was mixed well with Witepsol $\mathrm{H} 15$ at $60^{\circ} \mathrm{C}$. Then, morphine hydrochloride, sieved by a 50 -mesh screen, was mixed with melted bases (60 mg/1.6 g suppository) and dispersed homogeneously. The resulting mixture was then poured into plastic molds and allowed to cool at room temperature. Separately, Witepsol H15 suppository was prepared following the same procedure (30 mg of morphine/1.6 g suppository). Prepared suppositories were stored at $4{ }^{\circ} \mathrm{C}$ until use.

Differential Scanning Calorimetry (DSC) Analysis DSC thermograms were obtained using a DSC 2920 system 
(TA Instruments, New Castle, DE, U.S.A.). A PGEF and Witepsol H15 (2:8 by weight) were melted and mixed at $60{ }^{\circ} \mathrm{C}$, and solidified at room temperature. The resulting mixed base was milled, weighed $5 \mathrm{mg}$ in an aluminum pan and heated from 10 to $80^{\circ} \mathrm{C}$ at a rate of $2{ }^{\circ} \mathrm{C} / \mathrm{min}$ to obtain a DSC thermogram. An empty pan was set as a reference for each mixed base examined.

Measurement of Viscosity A PGEF and Witepsol H15 were melted and mixed at the arbitrary ratio at $60^{\circ} \mathrm{C}$, and solidified at room temperature. The apparent viscosity of mixed bases (approximately $1 \mathrm{~g}$ ) was measured with a cone and plate viscometer (Visconic ${ }^{\circledR}$ model E, Toki Sangyo Co., Ltd., Tokyo) at $37^{\circ} \mathrm{C}$.

In Vitro Release Study The release study was performed by PTSW-type rotating dialysis cell (Pharma Test, Hamburg, Germany). ${ }^{10}$ ) The dissolution medium was $900 \mathrm{ml}$

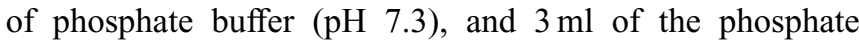
buffer was placed in the rotating cell. The cell was rotated at $25 \mathrm{rpm}$ and the dissolution medium was maintained at $37^{\circ} \mathrm{C}$. In order to shear the melted suppository, a Teflon stirring bar $(f=6 \times 30 \mathrm{~mm})$ was placed in the rotating cell. The drug concentration in the dissolution phase was assayed spectrophotometrically at $240 \mathrm{~nm}$.

The release profile was analyzed based on Higuchi's model, ${ }^{11-13)}$ where the cumulative amount $(Q)$ of morphine released versus time was described by the following equation:

$$
Q=k_{\mathrm{H}} \cdot t^{1 / 2}
$$

where $k_{\mathrm{H}}$ is the Higuchi's rate constant. The value of $k_{\mathrm{H}}$ was obtained as a slope of the linear portion of $Q$ versus $t^{1 / 2}$ plot for each mixed base by the least squares method.

In Vivo Absorption Study Male Beagle dogs (8$12 \mathrm{~kg}$ ), maintained at $20-26^{\circ} \mathrm{C}$ and $40-70 \%$ humidity, were used for all experiments. Prior to the experiment, the fecal content in the rectal canal was reduced by fasting for $24 \mathrm{~h}$. After rectal administration, $3 \mathrm{ml}$ of blood samples were collected from antebrachium cephalic vein using heparinized syringes, and plasma was obtained by centrifugation. For the intravenous administration, $2.5 \mathrm{ml}$ of morphine hydrochloride aqueous solution $(1 \mathrm{mg} / \mathrm{ml})$ was injected from antebrachium cephalic vein. All investigations were performed after approval by our local ethical committee at Dainippon Pharmaceutical Co. Ltd. and Okayama University in accordance with "Principles of Laboratory Animal Care (NIH publication \# 85-23)".

Analytical Method The plasma concentration of morphine was assayed by the HPLC (high-pressure liquid chromatography) method with some modifications. ${ }^{14)}$ Briefly, 0.5 $\mathrm{ml}$ of plasma was added to a test-tube containing $1.5 \mathrm{ml}$ of ammonium sulfate buffer $(\mathrm{pH} 9.3)$ and $50 \mu \mathrm{l}$ of nalorphine hydrochloride solution $(2.74 \mu \mathrm{g} / \mathrm{ml})$ as an internal standard. This mixture was applied to a Bond Elut ${ }^{\mathbb{R}} \mathrm{C} 18$ cartridge $(\mathrm{GL}$ Sciences, Inc., Tokyo). The cartridge was washed with $2 \mathrm{ml}$ of ammonium sulfate buffer $(\mathrm{pH} 9.3)$. Morphine was eluted with $2 \mathrm{ml}$ of $10 \%$ acetonitrile solution in phosphate buffer $(\mathrm{pH} 2.1)$. After the eluted solution was mixed with $1.5 \mathrm{ml}$ of ammonium sulfate buffer ( $\mathrm{pH} 9.3$ ), the resulting mixture was treated on a second Bond Elut ${ }^{\circledR} \mathrm{C} 18$ cartridge in the same way, again. The eluted solution was evaporated to dryness at $50{ }^{\circ} \mathrm{C}$ under reduced pressure. The residue was dissolved in
$100 \mu \mathrm{l}$ of $10 \%$ acetonitrile solution in phosphate buffer $(\mathrm{pH}$ $2.1)$, and an aliquot of solution $(20 \mu \mathrm{l})$ was injected onto HPLC system. The HPLC was carried out using a pump (Model LC-10ADVp, Shimadzu, Kyoto, Japan), an auto injector (SIL-10ADVp, Shimadzu), an electrochemical detector (potential at $+550 \mathrm{mV}$; Model Coulochem-III, ESA, Inc., Chelmsford, MA, U.S.A.), equipped with a column (6.0 $150 \mathrm{~mm}$ ) packed with ODS C18 (YMC-Pack ODS-A, YMC, Kyoto). The mobile phase was a mixture of $0.1 \mathrm{M}$ sodium dihydrogen phosphate buffer (containing $10 \mathrm{~mm}$ dodecyl sulfate and $30 \mathrm{~nm}$ ethylenediaminetetraacetic acid disodium salt $($ EDTA $\cdot 2 \mathrm{Na})$ ), adjusted to $\mathrm{pH} 2.5$ with phosphoric acid-acetonitrile-methanol $(68 / 27 / 5 \mathrm{v} / \mathrm{v})$, and was delivered at $40{ }^{\circ} \mathrm{C}$ at a flow rate of $2.0 \mathrm{ml} / \mathrm{min}$. The coefficients of variation for the standard curve $(0.4-67.3 \mathrm{ng} / \mathrm{ml})$ ranged from 0.1 to $17.2 \%$, and the squared correlation coefficient was over 0.999 .

Pharmacokinetic Analysis The highest plasma concentration of morphine observed was employed as $C_{\max }$, and the time for $C_{\max }$ was defined as $T_{\max }$. The area under the plasma concentration of morphine versus time curve $(A U C)$ and the mean residence time $(M R T)$ from 0 to $24 \mathrm{~h}$ were calculated by the trapezoidal method.

Statistical Analysis Analysis of variance (ANOVA) was used to test the statistical significance of differences among groups. Statistical significance in the differences of the means among groups was determined by Duncan's method.

\section{RESULTS AND DISCUSSION}

DSC Thermograms and Viscosity of Mixed Bases of Witepsol H15 with PGEF Figure 1 shows the DSC thermogram of Witepsol H15-DAS750 as a typical example of the Witepsol H15-PGEF mixed bases, and endothermic peaks of the solid fat and the mixed base are presented in Table 1. Witepsol H15 showed an endothermic peak at $29.6^{\circ} \mathrm{C}$. When Witepsol H15 was mixed with DAS750, the main endothermic peak derived from Witepsol H15 was hardly shifted $\left(29.8^{\circ} \mathrm{C}\right)$, and the secondary peak $\left(39.9^{\circ} \mathrm{C}\right)$ was dissociated at the higher temperature side of the main endothermic peak. As shown in Table 1, it was confirmed that PS500 and HB750 showed the same properties as observed in the previous study. ${ }^{10)}$ In the case of HB750, briefly, the main endothermic peak derived from Witepsol $\mathrm{H} 15$ was slightly shifted to higher temperatures $\left(32.2^{\circ} \mathrm{C}\right)$, and secondary peak $\left(56.2^{\circ} \mathrm{C}\right)$ was clearly separated from the main

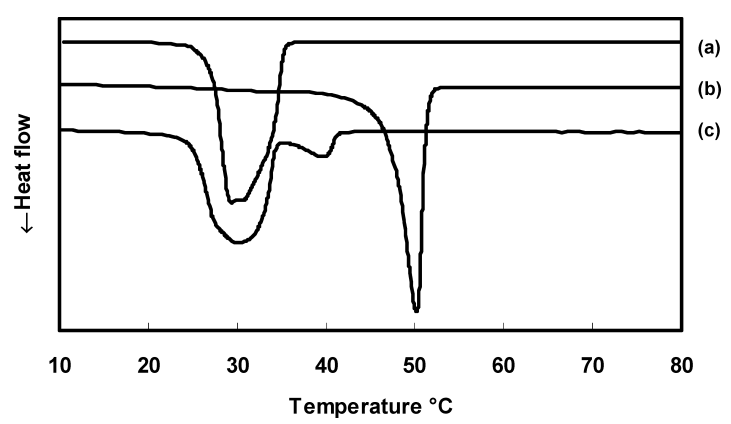

Fig. 1. DSC Thermograms of Witepsol H15-DAS750 Mixed Base (a) Witepsol H15, (b) DAS750, (c) Witepsol H15-DAS750 mixed base containing $20 \%$ DAS750. 
Table 1. Temperature of Endothermic Peaks $\left({ }^{\circ} \mathrm{C}\right)$ in DSC Thermograms for Mixed Bases of Witepsol H15 with PGEF

\begin{tabular}{lccc}
\hline \hline & & \multicolumn{2}{c}{$\begin{array}{c}\text { Mixed base with } \\
\text { Witepsol H15 }\end{array}$} \\
\cline { 3 - 4 } \multicolumn{1}{c}{ Base or solid fat } & $\begin{array}{c}\text { Original } \\
\text { peak }\end{array}$ & $\begin{array}{c}\text { Main } \\
\text { peak }\end{array}$ & $\begin{array}{c}\text { Secondary } \\
\text { peak }\end{array}$ \\
\cline { 3 - 4 } & & - & - \\
Witepsol H15 alone & 29.6 & 29.0 & 43.5 \\
Hexaglycerol pentastearate (PS500) & 52.2 & 29.8 & 39.9 \\
Decaglycerol decastearate (DAS750) & 50.2 & 32.2 & 56.2 \\
Decaglycerol heptabehenate (HB750) & 65.5 & 32.2 & \\
\hline
\end{tabular}

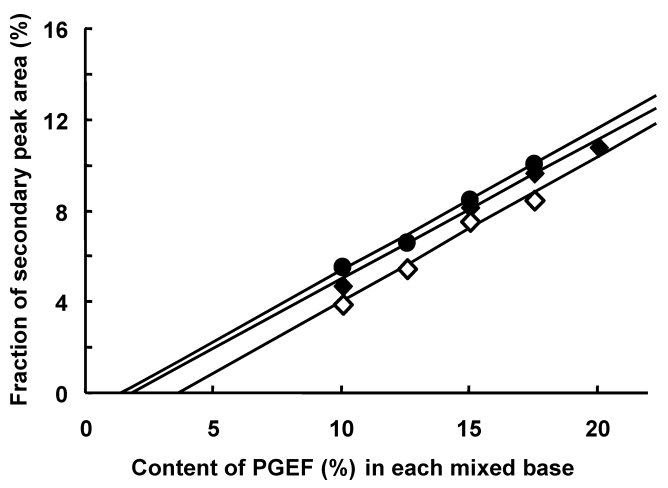

Fig. 2. Fraction of Secondary Peak Area in DSC Thermograms of Mixed Bases

Straight lines were obtained by the least-squares linear regression. DAS750; $(\bullet)$ HB750

endothermic peak. Table 1 also shows that the temperature of secondary peak, which is derived from each PGEF, is different among PGEFs. As PGEFs are prepared by esterification of polymerized glycerol with various fatty acids, their physicochemical properties are dependent on the length of polymerized glycerol and/or esterified fatty acids. PS500 and DAS750 are stearic acid esters of polyglycerol, while HB750 is a behenic acid ester. Therefore, the much higher temperature of the secondary peak for Witepsol H15-HB750 mixed base comparing with other mixed bases, might be ascribed to behenic acid.

Figure 2 presents the fraction of secondary peak area in DSC thermograms of Witepsol H15-PGEF mixed bases as a function of PGEF content. The fraction increased with the increase of PGEF content in every mixed base examined and the statistically significant correlation $(p<0.05)$ was observed with squared correlation coefficients of 0.990 (PS500), 0.980 (DAS750) and 0.992 (HB750), showing that the fraction un-melted at $37^{\circ} \mathrm{C}$ increased by adding each PGEF into Witepsol H15.

The apparent viscosity was measured for Witepsol H15PGEF mixed bases at $37^{\circ} \mathrm{C}$, and the relationships with the content of PGEFs are shown in Fig. 3. The linear and significant relationship was observed for each mixed base, and the squared correlation coefficients for PS500, DAS750 and HB750 were $0.934,0.959$ and 0.997 , respectively. These results indicate that the apparent viscosity of the mixed bases can be regulated quantitatively by adding PGEF into Witepsol H15, which could be ascribed to the amount of un-melted PGEF at $37^{\circ} \mathrm{C}$ in each mixed base as shown in Fig. 2. Figure 3 also shows that HB750 makes it possible to prepare more

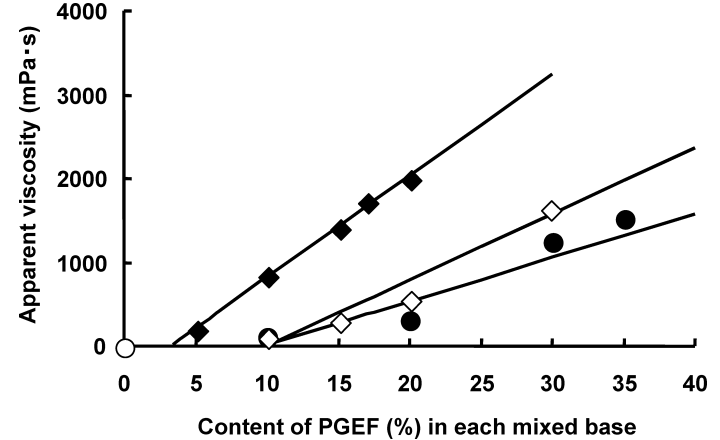

Fig. 3. Apparent Viscosity of Mixed Bases as a Function of PGEF Content

Apparent viscosity of mixed bases was measured at $37^{\circ} \mathrm{C}$. Each solid line was obtained by the least-squares linear regression. $(\bigcirc)$ Witepsol H15 alone; $(\bullet)$ mixed base with PS500; $(\diamond)$ DAS750; $(\diamond)$ HB750.

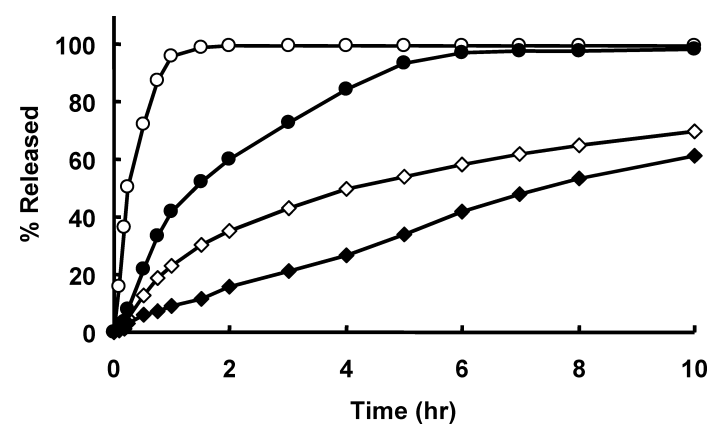

Fig. 4. Release Profiles of Morphine from Suppositories at $37^{\circ} \mathrm{C}$

(O) Witepsol H15 alone; (○) Witepsol H15-PS500 mixed base containing 20\% PS500; $(\diamond) 20 \%$ DAS750; $(\diamond) 20 \%$ HB750

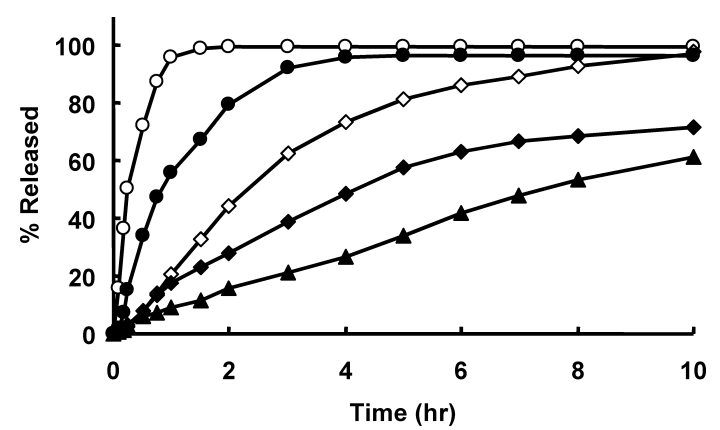

Fig. 5. Effect of HB750 Content on Morphine Release from Suppositories at $37^{\circ} \mathrm{C}$

(○) Witepsol H15 alone; (๑) Witepsol H15-HB750 mixed base containing 10\% HB750; $(\diamond)$ 15\% HB750; $(\diamond)$ 17\% HB750; ( $\Delta$ ) 20\% HB750. Each value represents the mean of 6 experiments.

viscous mixed base than PS500 and DAS750.

Drug Release from Witepsol H15-PGEF Mixed Base Suppositories Figure 4 shows the release profiles of morphine from suppositories made from Witepsol H15-PGEF mixed bases. The content of PS500, DAS750 or HB750 was $20 \%$. Addition of each PGEF to Witepsol H15 delayed the release of morphine from a suppository. As the addition of HB750 resulted in the slowest release of morphine among PGEFs examined, the effect of HB750 amount contained in the mixed base on the release of morphine was investigated (Fig. 5). The release of morphine from the Witepsol H15HB750 suppository decreased markedly with the increase in the weight fraction of HB750 in suppositories (Fig. 5). 
The analysis of the results of the in vitro release study showed that the release rate of morphine from suppositories could be described by Fickian diffusion model (Higuchi's model), suggesting that the drug release from the suppository is regulated by the drug diffusion through the melted base. ${ }^{11,12)}$ Then, the release rate constant of morphine $\left(k_{\mathrm{H}}\right)$ was calculated, and the relation with the weight fraction of HB750 in the Witepsol H15-HB750 mixed bases (Fig. 6A) or the apparent viscosity of the mixed bases (Fig. 6B) was examined. The result shows that the release of morphine from the suppositories decreases with the increase in weight fraction (Fig. 6A) and the apparent viscosity of the mixed bases (Fig. 6B). This result indicates that the release of morphine from Witepsol H15-HB750 suppositories could also be regulated by changing the apparent viscosity as reported previously. $\left.{ }^{9}, 10\right)$ As shown in Fig. 3, as the apparent viscosity of Witepsol H15-HB750 mixed base is significantly correlated with the content of HB750 in the mixed bases, the increased apparent viscosity by an un-melted solid fat would lead to the reduction of drug diffusion within the melted base.

Absorption of Morphine from Witepsol H15-HB750 Mixed Base Suppositories Figure 7 presents the plasma

(A)

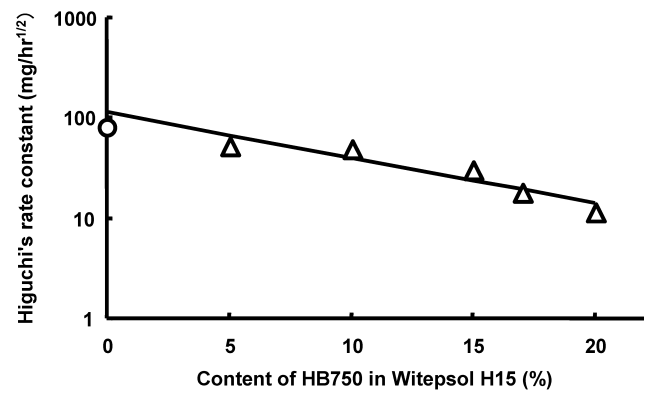

(B)

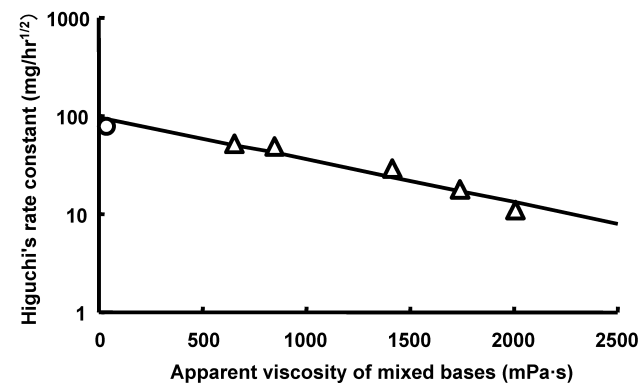

Fig. 6. Relationship between Higuchi's Rate Constant $\left(k_{\mathrm{H}}\right)$ and Weight Fraction of HB750 in Mixed Bases (A) or Apparent Viscosity of Mixed Bases (B)

The value of $k_{\mathrm{H}}$ was obtained based on the results shown in Fig. 5 and an additional experiment for $5 \%$ HB750 mixed base suppository according to the method described in Materials and Methods. The solid lines represent the least-squares linear regression lines. $(\bigcirc)$ Witepsol H15 alone; $(\triangle)$ Witepsol H15-HB750 mixed bases. concentration of morphine after single rectal administration of Witepsol H15-HB750 suppositories in dogs, and pharmacokinetic parameters are summarized in Table 2 . The dose of morphine hydrochloride was $60 \mathrm{mg} / \mathrm{dog}$ except for the suppository made from Witepsol $\mathrm{H} 15$ alone $(30 \mathrm{mg} / \mathrm{dog})$, because the rectal administration of $60 \mathrm{mg} / \mathrm{dog}$ by the Witepsol H15 suppository would lead to serious toxicity. But preliminary study showed that the linear pharmacokinetics of morphine after rectal administration of $60 \mathrm{mg} / \mathrm{dog}$ or less. After rectal administration of the Witepsol H15 suppository, plasma level of morphine increased rapidly with a $T_{\max }$ of $0.4 \mathrm{~h}$, followed by a fast decrease. On the other hand, plasma levels of morphine after rectal administration of Witepsol H15-HB750 suppositories gradually increased at early time periods and were kept at higher level for longer time periods, comparing with the Witepsol H-15 suppository.

Witepsol H15-HB750 suppositories showed the significant prolongation of MRT with the increase in HB750 contents, although there was no significant difference between $15 \%$ and $17 \%$ HB750. This prolongation of MRT was significantly correlated with the decrease in Higuchi's rate constant shown in Fig. $6(r=0.9772, p<0.01)$. The significant delay of $T_{\max }$ was observed, and the decrease in $C_{\max }$ was also significantly correlated with the decrease in Higuchi's rate constant $(r=0.9203, p<0.05)$. These results clearly indicate that the absorption of morphine was successfully sustained by mixed suppositories containing HB750. Relative bioavailability (BA) values for mixed base suppositories, compared with the Witepsol H15 suppository, are also summarized in Table 2. A mixed base suppository containing 10\% HB750 decreased the relative BA, but the reason might be that the real $C_{\max }$

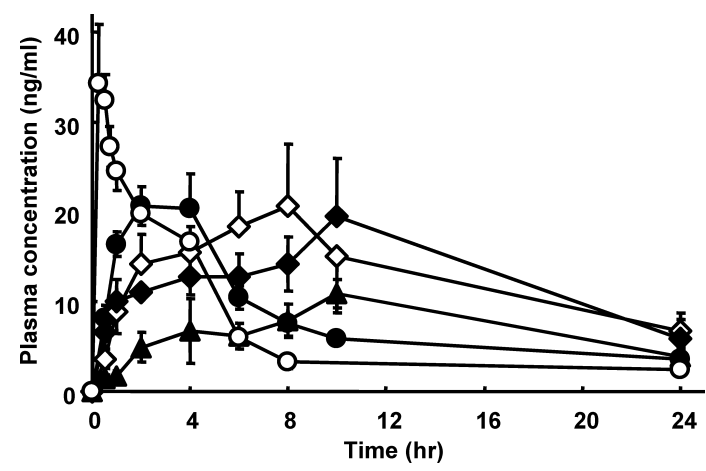

Fig. 7. Plasma Concentration of Morphine after Rectal Administration of Witepsol H15-HB750 Suppositories in Dogs

Witepsol H15 alone $(\mathrm{O})$; Witepsol H15-HB750 mixed base containing 10\% HB750 $(\bullet), 15 \%$ HB750 $(\diamond), 17 \%$ HB750 $(\diamond)$, and $20 \%$ HB750 $(\boldsymbol{\Delta})$. Dose: $60 \mathrm{mg} / \mathrm{dog}$ (Witepsol H15-HB750 suppositories); $30 \mathrm{mg} / \mathrm{dog}$ (Witepsol H15 suppository). Results are expressed as the mean \pm S.E. of $4-5$ experiments.

Table 2. Pharmacokinetic Parameters for Morphine after Rectal Administration of Mixed Base Suppositories of Witepsol H15 with HB750 in Dogs

\begin{tabular}{rcccccc}
\hline \hline Base & $\begin{array}{c}\text { Dose } \\
(\mathrm{mg} / \mathrm{dog})\end{array}$ & $\begin{array}{c}T_{\max } \\
(\mathrm{h})\end{array}$ & $\begin{array}{c}C_{\max } \\
(\mathrm{ng} / \mathrm{ml})\end{array}$ & $\begin{array}{c}M R T \\
(\mathrm{~h})\end{array}$ & $\begin{array}{c}A U C_{0-24 \mathrm{~h}} \\
(\mathrm{ng} / \mathrm{ml} \cdot \mathrm{h})\end{array}$ & $\begin{array}{c}\text { Relative } \\
\text { bioavailability }(\%)\end{array}$ \\
\hline Witepsol H15 alone & 30 & $0.4 \pm 0.1^{\mathrm{c}, \mathrm{d}, \mathrm{e}}$ & $39.1 \pm 10.1^{\mathrm{b}, \mathrm{c}, \mathrm{de}}$ & $6.6 \pm 1.3^{\mathrm{b}, \mathrm{c}, \mathrm{de}}$ & $136.0 \pm 32.5^{\mathrm{b}, \mathrm{c}, \mathrm{d}}$ & $100.0 \pm 23.9^{\mathrm{b}, \mathrm{e}}$ \\
with 10\% HB750 & 60 & $2.6 \pm 1.3^{\mathrm{c}, \mathrm{d}, \mathrm{e}}$ & $25.4 \pm 5.0^{\mathrm{a}, \mathrm{e}}$ & $8.2 \pm 1.4^{\mathrm{a}, \mathrm{c}, \mathrm{de}}$ & $192.1 \pm 27.1^{\mathrm{a}, \mathrm{c}, \mathrm{d}}$ & $70.7 \pm 10.0^{\mathrm{a}, \mathrm{c}, \mathrm{d}}$ \\
with 15\% HB750 & 60 & $6.0 \pm 2.8^{\mathrm{a}, \mathrm{b}, \mathrm{d}}$ & $26.0 \pm 8.7^{\mathrm{a}, \mathrm{e}}$ & $10.3 \pm 1.3^{\mathrm{a}, \mathrm{b}, \mathrm{e}}$ & $302.6 \pm 139.8^{\mathrm{a}, \mathrm{b}, \mathrm{e}}$ & $111.1 \pm 51.4^{\mathrm{b}, \mathrm{e}}$ \\
with 17\% HB750 & 60 & $12.0 \pm 8.5^{\mathrm{a}, \mathrm{b}, \mathrm{c}, \mathrm{e}}$ & $22.4 \pm 10.0^{\mathrm{a}, \mathrm{e}}$ & $10.7 \pm 2.8^{\mathrm{a}, \mathrm{b}, \mathrm{e}}$ & $303.9 \pm 116.1^{\mathrm{a}, \mathrm{b}, \mathrm{e}}$ & $111.8 \pm 42.7^{\mathrm{b}, \mathrm{e}}$ \\
with 20\% HB750 & 60 & $7.2 \pm 3.9^{\mathrm{a}, \mathrm{b}, \mathrm{d}}$ & $12.0 \pm 5.0^{\mathrm{a}, \mathrm{b}, \mathrm{c}, \mathrm{d}}$ & $12.2 \pm 1.2^{\mathrm{a}, \mathrm{b}, \mathrm{c}, \mathrm{d}}$ & $165.6 \pm 55.8^{\mathrm{c}, \mathrm{d}}$ & $60.9 \pm 20.5^{\mathrm{a}, \mathrm{c}, \mathrm{d}}$ \\
\hline
\end{tabular}

Results are expressed as the mean \pm S.D. of $4-5$ experiments. Relative bioavailability $(B A)$ was calculated by the following equation: relative $B A=A U C$ of each mixed base suppository/AUC of Witepsol H15 suppository $\times$ dose of morphine for Witepsol H15 suppository ( $30 \mathrm{mg}$ )/Dose of morphine for each mixed base suppository ( 60 mg). a,b,c,de $p<0.05$, compared with the Witepsol H15 alone, $10 \%$ HB70, 15\% HB70, 17\% HB70, 20\% HB70, respectively. 
could not be experimentally observed. In this case, $C_{\max }$ would be between 2 and $4 \mathrm{~h}$ after dosing. On the other hand, a mixed base suppository containing 15 or $17 \%$ HB750 did not decrease the relative bioavailability of morphine with prolonging MRT. However, the rectal administration of $20 \%$ HB750-containing suppository would lead to the decrease in bioavailability of morphine, although MRT was significantly prolonged. The decrease in the relative BA of morphine might be caused by the release rate that was too slow because of the high apparent viscosity of the mixed base. Furthermore, the effective surface area might be smaller for the mixed base suppository containing 20\% HB750 than other suppositories, because the base with higher viscosity and higher melting point could maintain the shape of suppository longer and retain in the original position of administration as reported by Yahagi et al. ${ }^{15)}$

These results clearly indicate that Witepsol H15-HB750 mixed base suppositories containing $15-17 \%$ HB750 could be the best preparation to maintain the plasma concentration of morphine by controlling the release of morphine from suppositories. Moreover, the in vivo absorption behavior of morphine could be reflected by the in vitro release characteristics of suppositories (Fig. 5) to some extent.

\section{CONCLUSIONS}

In the present study, controlled-release morphine suppositories were prepared by utilizing mixed bases of Witepsol H15 with PGEF such as PS500, DAS750 and HB750. HB750 showed the slowest release rate of morphine in the in vitro release study, and the release rate decreased with the increase in the apparent viscosity of the mixed bases, which could be ascribed to the decrease in the diffusion of morphine through the mixed bases. The in vivo absorption of morphine from suppositories was successfully prolonged with HB750, but Witepsol H-15-mixed base suppositories containing 15$17 \%$ HB750 could be promising ones because they sustained the plasma concentration of morphine without decreasing BA of morphine.

\section{REFERENCES}

1) Moolenaar F., Visser J., Leuverman A., Schoonen B. J. M., Int. J. Pharm., 45, 161-164 (1988).

2) Gourllay G. K., Clin. Pharmacokinet., 35, 173-190 (1998).

3) Cole L., Hanning C. D., Robertson S., Quinn K., Br. J. Clin. Pharmacol., 30, 781-786 (1990).

4) Moolenaar F., Meyler P., Frijlink E., Jauw T. H. Visser J., Int. J. Pharm., 114, 117-120 (1995).

5) Moolenaar F., Meijler W. J., Frijlink H. W., Visser J., Proost J. H., Eur. J. Pharmacol., 56, 219-223 (2000).

6) Kawashima S., Inoue Y., Shimeno T., Fujiwara H., Chem. Pharm. Bull., 38, 498-505 (1990).

7) Kibune Y., Moritani E., Takeshita Y., Kawashima S., Jpn. J. Hosp. Pharm., 17, 414-420 (1991).

8) Babul N., Darke A. C., Anslow J. A., Krishnamurthy T. N., J. Pain Symptom Manage., 7, 400-405 (1992).

9) Saito H., Takatori T., Higashi T., Nakamura Y., Chem. Pharm. Bull., 42, 1506-1509 (1994)

10) Takatori T., Shimono N., Higaki K., Kimura T., Int. J. Pharm., 278 , $275-282$ (2004).

11) Higuchi T., J. Pharm. Sci., 52, 1145-1149 (1963).

12) Schwartz J. B., Simnelli A. P., Higuchi W. I., J. Pharm. Sci., 57, 274 277 (1968).

13) Azechi Y., Ishikawa K., Mizuno N., Takahashi K., Drug Dev. Ind. Pharm., 26, 1177-1183 (2000).

14) Tan T., Kuramoto M., Takahashi T., Nakamura H., Nakanishi Y., Imasato Y., Yoshimura H., Chem. Pharm. Bull., 37, 168-173 (1989).

15) Yahagi R., Onishi H., Machida Y., J. Controlled Release, 61, 1-8 (1999). 